\title{
Coletivo (RE)Ação: um projeto popular na zona leste de Uberlândia, Minas Gerais
}

Bruno Aparecido de Paula Paim¹, Milena Abadia de Sousa²

\section{Resumo}

A finalidade deste artigo é mostrar e explicar o trabalho desenvolvido pelo Coletivo (RE)Ação. O Coletivo está vinculado ao Grupo de Pesquisa em Educação e Culturas Populares (GEPCPOP) do Programa de Pós-Graduação em Educação da Universidade Federal de Uberlândia (UFU). Percebendo ser tímido o diálogo estabelecido entre a Universidade e a(s) comunidade(s), o projeto busca colaborar para o ingresso de jovens de classe baixa na universidade, compreendendo-se a necessidade de desmistificar esta prática de exclusão social e mostrar que todos os espaços públicos são, por direito, de todos. Assim, propomos, neste texto, expor as ideias e os fundamentos que nos fortificam de forma coletiva e individual no campo em que escolhemos atuar: a educação, procurando, também, compartilhar as histórias e experiências vividas neste projeto de Educação Popular.

\section{Palavras-chave}

Educação Popular. Mídias Digitais. Coletividade. Extensão Universitária.

1. Graduando em História pela Universidade Federal de Uberlândia. E-mail: bpaim05@yahoo.com.br.

2. Graduanda em Geografia pela Universidade Federal de Uberlândia. E-mail: milenaabadia@hotmail.com. 


\title{
Coletivo (RE)Ação: a popular project in the east area of Uberlândia, Minas Gerais
}

Bruno Aparecido de Paula Paim*, Milena Abadia de Sousa**

\begin{abstract}
The purpose of this article is to explain a little about the work developed by Coletivo (RE)Ação. The Coletivo, is linked to the Research Group Popular Education and Cultures (GEPCPOP) of the Post-graduation Program of Education at the Federal University of Uberlândia (UFU). Realizing a shy dialogue established between the university and the community(s), the project tries to collaborate to the admission of low class young people at the University, understanding the need to demystify this practice of social exclusion and show that all public spaces are everyone's right. This way, we expose the ideas and principles that strengthen us collectively and individually in the field in which we act, education. In addition, we seek to share experiences in this popular education project.
\end{abstract}

\section{Keywords}

Popular Education. Digital Media. Collectivity. University Extension.

* Graduating student in History at the Federal University of Uberlândia. E-mail: bpaim05@yahoo.com.br.

** Graduating student in Geography at the Federal University of Uberlândia. E-mail: milenaabadia@hotmail.com. 


\section{Introdução}

A Zona Leste de Uberlândia, Minas Gerais, é uma região que sofre com o crescimento urbano desenfreado e sem planejamento. Um ambiente financeiramente pobre e socialmente violentado, com a presença de dois centros de detenção (para maiores e menores infratores), ruas sem asfalto e sem rede de esgoto. Além disso, as instâncias públicas chegam ao ponto de não reconhecerem certos bairros da região como partes municipais, mas sim como zonas de ocupação.

Pensando na necessidade de atuação e transformação deste cenário, o Grupo de Pesquisas em Cultura e Educação Popular $(\mathrm{GPECPOP})^{3}$ e a Ação Moradia ${ }^{4}$ desenvolvem, em parceria, trabalhos voltados para diferentes públicos da região. Nesta perspectiva, foi observada a existência de uma demanda que proporcionasse aos jovens daquela região novas alternativas. Assim, idealizamos um projeto que visasse à formulação de um curso preparatório aos alunos do ensino médio para a prova de seleção seriada da Universidade Federal de Uberlândia (UFU): o PAAES (Programa de Ação Afirmativa de Ingresso no Ensino Superior).

Reconhecemos que proporcionar a esses jovens de classe baixa um maior substrato para a seleção do ensino superior é Ihes atribuir condições diferentes da infeliz naturalidade educacional pública brasileira. Entretanto, o compromisso de educação popular que assumimos vai além desta tarefa. Trabalhamos, também, com outras ferramentas que gerem reflexões políticas, sociais, culturais aos alunos e, acima de tudo, a compreensão do sujeito como crítico atuante. Para isso, usamos como meio e meta o trabalho coletivo, o uso das mídias digitais e diversas parcerias com outros grupos de ações sociais.

Esta formulação é obra de nossa fuga do ensino meramente conteudista e convencionalmente exercido por outros cursinhos, que têm como prática reforçada pelos meios de ingresso universitário decorar as matérias e alimentar a competição exaustiva a um lugar que é um direito de todos: o ensino de qualidade. Assim, o Coletivo (RE) Ação representa um espaço que procura

[...] potencializar e institucionalizar as práticas educativas sem perder o foco da dimensão social e política da educação como possibilidade de transformação social. (SILVA, 2011, p. 3).

Construímos, dessa maneira, um espaço de criação e compartilhamento de experiências. Se por um lado os estudantes do (RE)Ação se reforçam e conquistam novos horizontes, os professores, por meio da ação extensiva, desenvolvem projetos e ganham conhecimento quanto à prática da licenciatura. Além da troca de saberes proporcionada em sala de aula, existe também a adquirida pelas discussões coletivas que o grupo se propõe. O grupo é constituído por alunos de graduação, mestrado e doutorado, todos ativos e se desenvolvendo sem hierarquias.

Desta maneira, está sendo construído um grupo de noções distintas, corroborando um com o outro na perspectiva de fortalecimento coletivo, fundindo conhecimento, prática, pesquisa, tecnologia e trabalho em equipe, abrangendo vários grupos, acadêmicos ou não, alcançando a meta de empoderamento coletivo e individual.

3. O Grupo de Pesquisa em Educação e Culturas Populares, vinculado ao Programa de Pós-Graduação em Educação da Universidade Federal de Uberlândia, é composto por vários subgrupos que buscam construir coletivamente conhecimentos com vistas a contribuir com o aprimoramento teórico e metodológico no campo da intervenção, trabalhando e investigando os processos de educação e culturas populares ligados às práticas escolares formais e não formais de ensino.

4. A Organização Não Governamental Ação Moradia está situada no bairro Morumbi, na cidade de Uberlândia. 


\section{Os primeiros passos de um projeto em construção}

Conhecemos as dificuldades que o ensino público de nosso país enfrenta, resultante, entre outras coisas, da pouca atenção dos órgãos responsáveis. Os currículos públicos educam à sua maneira, sem se preocupar com a necessidade de repaginar-se e atender a realidade. Além disso, atuam com a finalidade de justiça social, mas, dentro deste contexto, forçam seletividade, transformando a escola em um espaço de competição, incluindo uns, mas, principalmente, excluindo a maioria. Esse descaso culmina, mais tarde, no público que dominará as salas de aula do ensino superior, além de não proporcionarem alternativas para os que não almejam um futuro acadêmico.

A política de ingresso da UFU, com o intuito de proporcionar aos jovens de classe baixa um meio de lutar contra disparidade social estabelecida dentro da universidade, criou, em 2008, o PAAES. Esse programa propunha provas seriadas, com questões de múltipla escolha e uma redação, dispondo de $25 \%$ das vagas anuais oferecidas pela UFU. Assim, essas vagas seriam destinadas, exclusivamente, a estudantes que, comprovadamente, tivessem cursado os últimos quatro anos do ensino fundamental e que estivessem cursando o ensino médio na rede pública, conforme Resolução № 20/2008.

Essa medida assumida pela UFU propunha como objetivo qualificar as escolas públicas, democratizar o ensino e melhorar a educação. Porém, nota-se que essas medidas auxiliaram, principalmente, as escolas públicas centrais da cidade de Uberlândia e não se expandiu da forma esperada para os bairros periféricos. Isso acontece, pois, na maioria das vezes, os alunos e professores da periferia desconhecem essas informações. Não se tem programas de incentivo para esses alunos conhecerem a universidade e os processos seletivos que ela possui.
É em meio essa realidade é que o Coletivo (RE)Ação propôs um trabalho voltado para os estudantes do ensino médio público do bairro Morumbi e outros bairros vizinhos. Notamos que essa oportunidade, além de abarcar as medidas defendidas pela Universidade, também alcançaria êxito quanto à questão do número de candidatos por vaga, significativamente menor que os demais meios de seleção. Além disso, estaríamos difundindo o verdadeiro sentido de universidade, que, para nós, representa ou deveria representar um ambiente educacional de qualidade, que abarque diferentes classes econômicas e múltiplas experiências culturais.

\section{O uso das mídias digitais em nosso trabalho}

As mídias digitais estão cada vez mais constantes na vida dos indivíduos, seja no simples ato de procurar um vídeo em um determinado site, estabelecerem contatos nas redes sociais, promoverem divulgações por múltiplos interesses. Enfim, este é um meio no qual se estabelece trocas de informações, acumuladas ou em tempo real, permitindo que os indivíduos se manifestem individualmente ou em grupos, sem entraves de espaço e tempo.

Nesta situação, cabe ao educador fazer parte deste meio, pois o cotidiano e as experiências dos estudantes devem ser considerados no processo de ensinoaprendizagem. Nessas atividades, cabe a construção de experiências de forma coletiva, pensando e repensando, de forma crítica, os benefícios ou não que as tecnologias contemporâneas nos oferecem, pois, certamente, estão influenciando as gerações.

Um dos instrumentos que utilizamos em nosso trabalho são as Tecnologias de Informação e Comunicação (TICs). Não queremos com isso que sua utilização seja apenas uma forma facilitadora de trabalho ou mais um simples 
objeto dentro da sala de aula. Nosso objetivo é contribuir para que as informações sejam trabalhadas de forma crítica, incentivando o manifesto e a criatividade dos discentes.

Ao trabalhar com a importância da abordagem das TICs como instrumentos em sala, projetando-a de forma interativa e crítica no processo de ensino-aprendizagem, Garcia e outros nos esclarece que

[...] é insuficiente ser capaz de usar as tecnologias apenas como suporte para a informação. Trata-se de compreender a gênese da cultura digital instaurada na sociedade e sobre tudo na educação, suas relações com a prática pedagógica e suas possibilidades para a criação e interatividade. (GARCIA et al., 2011, p. 84).

Este tem sido um desafio para nós professores: instaurar, em sala, artifícios que proporcionem a reflexão dos alunos, mas sempre fazendo com o intuito de atribuir-lhes o conhecimento por meio da reflexão, do trabalho de análise e trocas coletivas, diferentemente da ação normalizada nas escolas, em que o aluno é mero receptor de conhecimento. Desta forma, buscamos construir, em conjunto, uma cultura que não fique refém das máquinas ou dos atributos que eles nos proporcionam, mas criar um contexto em que ambos dialoguem.

Ainda dentro deste veículo de acessibilidade que as mídias modernas nos proporcionam, deparamo-nos com a possibilidade das redes sociais de nos auxiliar. Dessa forma, reconhecemos ser uma maneira de sociabilizar, formada graças a dois elementos - os atores e suas conexões - de forma que as redes seriam "uma metáfora para observar os padrões de conexão de um grupo social, a partir das conexões estabelecidas entre os diversos atores" (RECUERO, 2009, p. 24).

Assim, as redes sociais nos serviram como espaço, em tempo real ou não, para trocarmos informações, manter contato entre alunos e professores, causando proximidade entre ambos, desconstruindo um padrão enrijecido estabelecido culturalmente.

\section{O trabalho coletivo: parcerias e discussões}

No começo do projeto, confundíamos qual era o caráter do trabalho que estávamos desenvolvendo, no que diz respeito à implementação de um cursinho alternativo ou popular. Essa dúvida surgiu pela dificuldade que tínhamos de nos separar da metodologia pela qual fomos ensinados, ou seja, por meio de métodos conteudistas, fragmentados, sem a ambição de criticidade e sem levar em consideração nossas experiências. Ainda nessa rota, assumindo nosso projeto pelo viés alternativo, cumpriríamos as mesmas perspectivas de entidades que fortalecem o sistema competitivo das vagas superiores e públicas, esquecendo que o foco não é a universidade e, sim, o indivíduo.

A partir de nossas reuniões e de discussões veementes, percebemos, de maneira coletiva, que desejávamos construir um espaço de reflexão sociocultural, no qual cada estudante fosse capaz de se reconhecer dentro daquela dimensão de estudo, utilizando o projeto como forma de (re)ação, como uma ferramenta capaz de construir seu próprio futuro. É deste modo que externamos e reconhecemos o nosso entusiasmo pela educação popular, o que gerou, por consequência, a ação não de um cursinho, mas de um projeto interessado em fazer "com" os sujeitos e não "para" eles, não delineado pelas imposições elitistas e meritocráticas de nossa sociedade.

A coletividade assumiu, a partir de então, entrelaces diversos dentro do trabalho, troca de conhecimentos entre indivíduos e grupos, ampliação do direito de voz e reconhecimento, na forma de discussões, parcerias e definições. Em primeiro lugar, procuramos arquitetar 
nossos conteúdos interativamente, construindo diálogos de diferentes disciplinas em torno do mesmo assunto. Em outras oportunidades, o coletivo se dava pelo planejamento de um determinado conteúdo por vários professores. Em segundo lugar, buscamos diferentes grupos de reflexão em que pudéssemos criar parcerias e desenvolver oficinas ${ }^{5}$. Assim, exploramos fundamentos pedagógicos e criativos para que melhor nos conhecêssemos, entendêssemos o surgimento cultural e artístico de atividades pouco reconhecidas, mas constantes em nosso cotidiano. Abraçamos culturas que pertencem às nossas raízes e que são continuamente desvinculadas de nossos conhecimentos, a fim de engessar uma mentalidade imposta e homogênea. Adentramos, ainda, às margens tecnológicas cada vez mais presentes em nossas vidas, para discutí-las e compreender o arcabouço que nos oferecem. Em terceiro lugar, destacamos a construção de um espaço em que o diálogo foi uma prática constante. Entendemos que somente existirá uma prática coletiva se todos tiverem direito a participar das escolhas do grupo. Isto gera democracia, não simplesmente pelo direito de escolha, mas por propor encaminhamentos, expor desapontamentos e proposições, estar dentro do movimento e não somente diante dele.

Com este intuito, levamos aos estudantes as possibilidades que surgiam em meio ao projeto, tanto no que requeria decisões simples quanto as mais complexas. Fazíamos exposições e possibilitávamos o envolvimento dos estudantes em todos os sentidos. Assim, pudemos nos direcionar quanto aos seus interesses, conhecer e reconhecer que cada um tem um posicionamento diferente e que, juntos, são construtores de sua realidade.

\begin{abstract}
Nessa dimensão, o intelectual coletivo aparece como aquele que, dentro das especificidades de suas competências profissionais, atua como mobilizador das diversidades em torno de eixos comuns. Potencializa a reflexão coletiva em torno das diversidades reais, das lutas reivindicatórias em contextos determinados, sistematizando "utopias realistas", registrando, analisando e sistematizando as experiências construídas. (OLIVEIRA; KLINKE, 2011, p. 47).
\end{abstract}

Procuramos, a partir desta metodologia, desconstruir um saber imposto e hierárquico, sem dominação. Buscamos construir uma rede de conhecimentos em que cada nó assumia sua importância e fazia-se legítimo e horizontal ao outro.

\section{Metas do Coletivo (RE)Ação}

O Coletivo (RE)Ação estabelece-se como um espaço de militância, que procura com e em seus alunos estabelecer diálogos e enxergar neles perspectivas e necessidades. Não se programa em uma aparência vertical, em que o correto é estabelecido de cima para baixo, pois, para que existam mudanças, o coletivo precisa reconhecerse em seus meios, estabelecendo ideologias diversas que caminhem focadas nos sujeitos múltiplos de nossos espaços de convivências.

Vivemos em uma sociedade que extirpa o conhecimento popular e, por consequência, discrimina a cultura em questão. É neste viés que a educação se instaura, (im)posta de forma individualista. Essas amarras compiladas pela

5. Trabalhamos ao longo de 2012 com alguns grupos do Programa Institucional de Bolsas de Iniciação à Docência (PIBID), vinculados aos cursos de Pedagogia, Matemática, Artes da UFU. O primeiro possibilitou-nos atividades de aproximação e de conhecimento com os estudantes; o segundo trabalhou o uso de tecnologias por meio da robótica; o terceiro desenvolveu atividades sobre a cultura dos grupos indígenas. Cada grupo, em sua área, procurou alcançar aspectos nos espaços culturais e sociais dos jovens, de forma que cada um deles refletisse seu cotidiano, (re)conhecesse o próximo e, por consequência, buscasse compreender o mundo de modo mais crítico. 
educação direcionam as pessoas para a exclusão pormeiodeumdiscursoimpositivoedisciplinado.

Assim como Freire (2011), acreditamos que a educação tem outro sentido. Ao compreender essa sociedade elitista e discriminadora, o autor sabiamente identifica o sentido de educação:

Por isso, desde já, saliente-se a necessidade de uma permanente atitude crítica, único modo pelo qual o homem realizará sua vocação natural de integrar-se, superando a atitude do simples ajustamento ou acomodação, aprendendo temas e tarefas de sua época. (FREIRE, 2011, p. 61).

Desta forma, justificamos e reafirmamos o Coletivo (RE)Ação como um espaço conjunto, buscando indagações para as atitudes humanas de seu tempo, formatando, como modelo de estudo, a lógica da troca de experiências como ensino-aprendizagem, em que o grupo caminha, empoderando-se dentro e fora da sala de aula.

\section{(In)Conclusão}

Podemos dizer que o intuito maior do nosso projeto foi o de instigar sonhos nesses jovens, que, na maioria das vezes, desejam apenas concluir o ensino médio e arrumar um emprego ou, no máximo, fazer um curso profissionalizante para conseguir um trabalho melhor. Sonhamos juntos, então, que a universidade é pública e que todos deveriam ter direito, mas deixamos claro que isso ainda é só uma teoria e que na prática é totalmente diferente.

Entendemos que a Universidade deve ser um espaço aberto para a comunidade em seu mais amplo significado e não um lugar restrito a pessoas e ideologias que reforçam hegemonias. Por outro lado, esta deve ser entendida como opção e não como salvação.

Coletivo é onde todos se veem parte do processo, onde cada um contribui da sua forma para a construção de ideias e de sonhos. Ainda temos muito para aprender, porém isto é uma circunstância gradativa, pois nos empoderamos mediante conhecimentos que a militância contra as disparidades nos promove. Enriquecemos-nos de forma verdadeira ao ver nos rostos dos nossos jovens a vontade de fazer a diferença e vencer desafios. A partir de 2013, o Coletivo (RE)Ação trabalhará com a atual forma de ingresso na UFU: o Exame Nacional do Ensino Médio (ENEM). Sabemos que virão outras dinâmicas, novos membros e, com isso, novas formas de trabalho, porém buscaremos manter a máxima que compreende a capacidade crítica em seus meios, pois, para nós, esta é a lógica capaz de refletir em indivíduos e coletivos a verdadeira "reação".

\section{Referências}

FREIRE, P. Educação como prática da liberdade. 14 ed. Rio de Janeiro: Paz e Terra, 2011.

GARCIA, M. F. et al. Novas competências docentes frente às tecnologias digitais interativas. Teoria e Prática da Educação, Maringá, v. 14, n. 1, p. 79-87, jan./abr. 2011.

OLIVEIRA, C. S. de; KLINKE, K. O PRAXIS: coletivo de educação popular e a universidade em movimento. In: SANTOS, B. P.; NOVAIS, G. S.; SILVA, L. C. da. (Org.). Educação popular em tempos de inclusão: pesquisa e intervenção. Uberlândia: EDUFU, 2011.

RECUERO, R. Redes sociais na Internet. Porto Alegre: Sulina, 2009. (Coleção Cibercultura). 
SILVA, S. G.; PEREIRA, V. A. Aproximação entre universidade e comunidade: relatos e vivências no contexto de cursos pré-universitários populares. In: CONGRESSO NACIONAL DE EDUCAÇÃO (EDUCERE), 10., 2011, Curitiba, Anais... Curitiba: Champagnat, 2011. Disponível em: <http:// educere.bruc.com.br/CD2011/pdf/4339_2791.pdf>. Acesso em: 30 jun. 2013.

UNIVERSIDADE FEDERAL DE UBERLÂNDIA. Conselho Universitário. Resolução n 20/2008. Disponível em <http://www.transparencia.ufu.br/>. Acesso em: 30 jun. 2013.

Submetido em 30 de maio de 2013.

Aprovado em 17 de julho de 2013. 